his eyes in the dark till the next observation. There were twenty-five observers. The result seems worthy of notice.

(I) Of the twenty-five all agree that the colour of the filament is at first very pale. Thirteen call it very pale yellow, three call it white, seven a faint pink, two a bluish white.

(2) All agree that, as the temperature rises, the tint grows deeper and redder, passing through orange before reaching crimson. The words used to designate the final tint reached in the experiment vary from deep reddish orange to copper colour, dark red, blood red, crimson.

I may add that some of the observers had had considerable practice in observation, and their eyes were known to be normal so far as the perception of the tints of the visible spectrum is concerned. There is no reason to suppose that more than one, or two at most, possessed any abnormal sense of colour.

Assuming that in the cases of iron and carbon light of greater frequency of vibration is emitted as the temperature rises, in addition to the light emitted at lower temperatures (the vibrations causing which are merely increased in amplitude), is it not possible (I) that the selective power of the pigments of the retina at first scarcely comes into play, the slower vibrations acting on all to a certain extent, on the red more than the green, and the green more than the violet, in the normal eye? or (2) Does not the fact that all colours are more difficult to distinguish in a faint light, e.g. moonlight, make it likely that very weak irritation of any part of the retina (I mean a part which causes the sensation of light, and that coloured, when the irritation is stronger) is perceived as "light," the indication of specific absorption not being strong enough in comparison with the total amount of irritation to produce the sensation of any special colour in the light perceived? or lastly, if we do not make the above assumption, it would seem that iron and carbon at all events emit, when first visible, light of far wider limits of frequency of vibration than, so far as I know, is generally admitted.

Some photographic experiments which I hope may throw fresh light on the subject have been begun.

Eton College Laboratory, April 4.

T. C. Porter.

\section{Self-Registering Weather-cock.}

I SHOULD be grateful if any of your readers would kindly recommend me a simple, inexpensive instrument, to automatically register the movements of a weather-cock above the roof.

Such an appliance must roughly indicate the direction of the wind at the time being.

Some years ago, a London builder put me up a very ex pensive instrument, which, beyond making considerable noise, was utterly useless.

30 Sussex Square, Brighton, April I I.

J. LAWRENCE-HAMILTON.

\section{THE ROLLING OF SHIPS.}

$\mathrm{O}^{\mathrm{se}}$

$\mathrm{NE}$ fact that often strikes the thoughtful traveller by sea is that, notwithstanding the great and numerous improvements of recent years which have made life on shipboard pleasant and luxurious, little or nothing has been done to steady a vessel when she meets with waves that set her rolling heavily from side to side. The tendency seems to be rather in the direction of increased than of diminished rolling; for the steadying influence of sails, which makes the motion so easy and agreeable in a sailing ship, is fast disappearing in large steamers. Masts and sails add appreciably to the resistance of large fast steamers; so they have been cut down in size year by year till such fragments of sail as still remain are so small compared with the size of the ship as to retain little power to reduce rolling.

Shipowners and seamen do not show much sympathy with the discomfort and misery that rolling causes to most passengers. They perhaps get anxious about an occasional vessel that acquires the evil reputation of being a bad roller, because passengers may be frightened away and the receipts fall off in consequence ; but beyond wishing, or attempting, to deal with abnormal cases, nothing seems to be thought of. Rolling is considered incurable, or as not of sufficient importance to trouble about. Yet there is nothing which would contribute so directly to the comfort of landsmen at sea, or do so much to change what is for many misery and torture into comfort, as to check and reduce as far as possible the rolling proclivities of ships.

The laws which govern rolling are now well understood, and it is strange that this knowledge has not enabled an effective means of control to be devised. What is stranger still is that well-known means of mitigating rolling-such as the use of bilge keels-are employed in but very few cases. A ship rolls about a longitudinal axis which is approximately at her centre of gravity, and the rolling is practically isochronous at moderate angles in ordinary ships. The heaviest rolling occurs when the wave-period synchronizes with the natural period of oscillation of the ship. Many vessels are comparatively free from rolling till they meet waves of this period, and if such meeting could be avoided, excessive rolling could be prevented. Some vessels have periods as long as fifteen to eighteen seconds for the double oscillation, and as these would require to meet with waves 1300 to I 500 feet in length, in order to furnish the conditions of synchronism, it is seldom that they suffer from heavy or cumulative rolling. Such waves are, however, not rare in the Atlantic.

The limits of heavy rolling are fixed, of course, by the resistance offered by the water and air to the transverse rotation of the ship, which is very great because of the large areas that directly oppose motion in a transverse direction. But for this resistance, and the condition that rolling is only isochronous within moderate angles of inclination, a few waves of the same period as that of a ship would capsize her.

The two most obvious modes of preventing heavy rolling are, therefore, (I) to make the period of rolling of a ship as long as possible, so as to reduce the chances of meeting waves whose period will synchronize with it, and (2) to increase the resistance to rolling. The period of a ship varies directly as her radius of gyration, and inversely as the square root of her metacentric height. Hence the period may be increased by increasing the moment of inertia of the ship, or by decreasing the metacentric height. In armoured war-vessels the moment of inertia is large, on account of the heavy weights of armour on the sides, and the heavy guns that are either placed at the side or high up above the centre of gravity. Ordinary steamers have no such weights concentrated at great distances from the centre of gravity, and their moments of inertia are determined by the distribution of material in the hull that is fixed by structural conditions and by the stowage required for their voyages. Metacentric height cannot be reduced below a certain amount, which is necessary to prevent too easy inclination of the ship, or crankness, in still water. On the whole, we may regard the longest periods that the largest ships are likely to have with advantage to be about those named above, i.e. fifteen to eighteen seconds.

Length of period cannot give immunity against occasional heavy rolling; but increase of resistance reduces the angles of roll at all times, and especially when the angular velocity is greatest and the rolling is worst. Such resistance is furnished by the frictional resistance of the bottom of a ship and by the direct resistance of projecting parts of the bottom, such as the keel and the large flat surfaces below at the stem and stern. This resistance can be largely increased by means of bilge keels. The value of bilge keels is recognized in the Royal Navy, and the ships of the Navy have been fitted with them for many years with highly beneficial results. The advantage of bilge keels was proved beyond all doubt many years ago by careful experiments made in this country and in France; and the late $\mathrm{Mr}$. Wm. Froude showed, by the trials he made of H.M.S. Greyhound

NO. I I 72 , VOL. 45] 
twenty years ago, that bilge keels of excessive size--3 feet 6 inches deep, and 100 feet in length, on a vessel 172 feet long-had only an insignificant effect upon speed throughout great differences of trim.

It is strange that the mercantile marine should not yet have adopted bilge keels, and obtained the undoubted advantage they give in steadiness. The number of ships that have them is comparatively few. There is an almost universal opinion and prejudice against their use, and the large it and finest passenger steamers have no bilge keels. This is in spite of the fact that, in cases where bilge keels have been fitted to try to check heavy rolling-and they have been of suitable size and properly placed-it has been found that the angles of rolling have been reduced by nearly one-half. There is a prevalent belief - which has no foundation in fact-that bilge keels are very detrimental to speed. We have said that Mr. Froude's experiments showed the contrary, even on trials made in still water; but it appears certain that at sea any trifling loss of speed which still-water trials might show would be more than compensated for by gain in speed when the vessel is prevented from rolling through large angles from side to side, and undergoing great changes of underwater form at every roll. Experience with ships that have had bilge keels added after running for some time without them shows that there has been no appreciable difference of speed or increase of coal consumption on their voyages.

Another, and a more heroic, method of stopping or reducing rolling would be to counteract the inclining moment of the ship caused by the ever-changing inclination of the waves by an equal and opposite moment, which would vary as the inclining moment varies. This has been attempted at different times and in various ways. It is essential to any degree of success, however, that the opposing moment brought into operation should be completely under control, so as always to act in the manner and to the extent required. The attempts to obtain a steady platform by freely suspending it, and making it independent of the roliing of the ship, have failed-apart from the practical difficulties of carrying out such an arrangement on a large scale-because the point of suspension oscillates when the ship rolls, and the platform acquires a rolling motion of its own. Weights, made of heavy solid material, which move from one side to the other of a ship subject to the action of gravity and rotation, fail because they cannot be made to act continuously in the manner required.

A degree of success has been achieved by admitting water into a suitably prepared chamber and leaving it free to move from side to side as the ship rolls. This has been done in several ships of the Navy, the case of the Inflexible being that which was the most carefully experimented upon. The movement of this internal water follows the inclination of the ship, but it lags behind, and thus tends to reduce the inclination. Its effect can be regulated by the quantity of water admitted into the chamber and by its depth. The Inflexible Committee state in their report that comparatively small changes in depth increase or diminish largely the extinctive power of the water. For various reasons-one of which is that while such a chamber is very effective in a moderate sea it fails in a rough sea when the rolling of the ship is greatest-and perhaps partly on account of the destructive and disturbing effect of 100 tons or more of water rushing from side to side of a ship over 60 feet wide-these water.chambers appear to have gone out of use in the Navy, and they have been given up in the City of New York and City of Paris, which vessels were said to be fitted with them when first built and placed upon the Atlantic.

Mr. Thornycroft has devised a means of checking rolling by moving a weight, under strict control, from side to side of a vessel so as to continuously balance, or subtract from, the heeling moment of the wave slope. It consists of a large mass of iron in the form of a quadrant of a circle, which is placed horizontal, with the centre on the middle line of the vessel, and there connected with a vertical shaft. The shaft is turned by an hydraulic engine, which is very ingeniously controlled by an automatic arrangement. The heavy iron quadrant is swept round from side to side, revolving about its centre, to the extent that is required to counteract the beeling moment. In a paper read on the 6th instant before the Institution of Naval Architects, Mr. Thornycroft said :-

"The manner in which the controlling gear works will be better understood if we imagine a vessel remaining upright among waves, while near the centre of gravity of the ship we place a short-period pendulum suspended so as to move with little friction; this will follow the change in the apparent direction of gravity without appreciable loss of time, so that any change in the wave angle and apparent direction of gravity cannot take place without due warning, which will indicate the time and amount of the disturbance. It is therefore only necessary to make the motion of the ballast bear some particular and constant ratio to the motion of this short-period pendulum to keep the balance true. The inertia of a heavy mass will cause some loss of time, as we can only use a limited force for its control ; but it is possible to accelerate the phase of motion and overcome this difficulty so far as to get good results.

"If, now, we imagine the ship to roll in still water, the effect of the combination just described will be to balance the ship's stability for a limited angle; but this defect is removed by the introduction of a second pendulum of long period, which tends to move the ballast in the opposite direction to the first one, and enables the apparatus to discriminate between the angular motion of the water and that of the vessel.

"I find, however, that the long-period pendulum is rather a delicate instrument, and that its function can be served by a cataract arranged so as to always slowly return the ballast to the centre, and this device has the effect of accelerating the phase of motion, which, in some cases, we also require.

"We are therefore able, by very simple parts, to construct an apparatus which will indicate the direction and amount of motion necessary to be given to the ballast at a particular time so as to resist the wave effort; this power of indicating may be converted into one of controlling by suitable mechanism. The loss of time due to inertia of the necessary ballast is not always unfavourable when the apparatus has to extinguish rolling motion, the greatest effect being obtained when the ballast crosses the centre line of the ship at a time when it is most inclined to the water surface, and this corresponds to a quarter of the phase behind the motion of the short pendulum."

The apparatus has been working for some time in the steam yacht Cecile with very good results. What the objections may be to applying it to the largest passenger steamers remains to be seen. A moving weight of something like 100 or 150 tons would probably be required in such vessels. The power necessary to control the movement of the weight appears to be small, and Mr. Thornycroft's invention seems at any rate to show the way towards obtaining the long-desired boon of substantially reducing, if not checking altogether, the rolling of ships. If it succeed in doing upon a large scale only a portion of what is claimed for it in the way of anticipating and counteracting the heeling effect of waves, without the possibility of acting in an erratic or undesirable way, we may hope to see it adopted some day in passenger steamers.

NO. I I 72, VOL. 45 ] 